\title{
Darcy Ribeiro: a questão indígena, representação literária e suas múltiplas interfaces
}

Haydee Ribeiro Coelho Universidade Federal de Minas Gerais

Resumo: Para enfocar a questão indigena, representação literária e suas múltiplas interfaces a partir de alguns textos de Darcy Ribeiro, situo primeiramente o indianismo, como tema literário, com base no ensaio de Walnice Nogueira Galvão que retorna a este aspecto, tendo em vista a publicação de Maíra em 1976. Em seguida, remeto a outros estudos e ressalto que, antes de publicar seu primeiro romance, Darcy Ribeiro produziu uma importante, extensa e complexa obra antropológica da qual saliento Os índios e a civilização. Maíra, ao apresentar visóes diferenciadas sobre os indios a partir de si mesmos e dos brancos civilizados, possibilita o diálogo com uma gama variada de textos históricos e antropológicos como A fundação do Brasil, livro organizado por Darcy Ribeiro e Carlos de Araújo Moreira Neto e, ainda, O povo brasileiro: a formação e o sentido do Brasil, com destaque para o capitulo "Enfrentamento dos mundos". Em Diários índios, Darcy Ribeiro narra, de forma cronológica, sua viagem ao norte do pais, para "estudar os descendentes dos velhos Tupinambá", o que propiciou focalizar o contato do antropólogo com os indios e o olhar destes para a escrita do branco sobre eles. A abrangência de Diários índios implicou um destaque para aspectos mais gerais do livro. Palavras-chave: Questão indígena, Representação literária, Darcy Ribeiro. 


\section{Revisitando caminhos e textos}

O indianismo reporta-se a muitos caminhos percorridos pela literatura e pela crítica brasileiras. Em "Indianismo revisitado", Walnice Nogueira Galvão abre seu trabalho com uma epígrafe, retirada de Formação da literatura brasileira, de Antonio Candido, o que não ocorre por acaso. Em seu estudo, o crítico afirma: "Teoricamente o nacionalismo independe do Romantismo, embora tenha encontrado nele o aliado decisivo". ${ }^{2}$ Para ele:

[...] o indianismo inicial dos neoclássicos pode ser interpretado como tendência para dar generalidade ao detalhe concreto. [...] O indianismo dos românticos, ao contrário, denota tendência para particularizar os grandes temas, as grandes atitudes de que se nutria a literatura ocidental, inserindo-as na realidade local, tratando-as como próprias de uma tradição brasileira. $^{3}$

Walnice Nogueira Galvão, compartilhando o pensamento de Antonio Candido, mostra que o índio na literatura brasileira não teve "muita sorte", depois do período romântico. Diferentemente, o indigenismo, nas letras hispanoamericanas, vigorava com muita força. A publicação de Maíra (1976) e sua grande repercussão propiciavam a retomada do tema. A partir desse acontecimento, Walnice revisita o assunto, evidenciando momentos do indianismo na literatura brasileira.

Ao referir-se ao romance de Darcy Ribeiro, destaca do mesmo autor o texto antropológico Uirá sai à procura de Deus, em que se baseou Gustavo Dahl para realizar o filme Uirá, um índio em busca de Deus (1975). Nessa mesma direção, menciona Como era gostoso o meu francês (1971), dirigido pelo cineasta Nelson Pereira dos Santos, evidenciando como o interesse pelo índio se fazia presente em outras artes.

Walnice Nogueira Galvão refere-se a obras e textos diversos que marcaram a literatura brasileira, tendo o índio como centro: O Uraguai (1769), de Basílio da Gama; O Caramuru (1781), de Santa Rita Durão; Iracema (1865), Ubirajara (1874) e o Guarani (1857), de José de Alencar; O índio Afonso (1873), de Bernardo Guimarães e Guesa errante (1867-1888), de Sousândrade. No

1. GALVÃO. Indianismo revisitado, p. 171-185.

2. CANDIDO. Formação da literatura brasileira, v. 2, p. 14.

3. CANDIDO. Formação da literatura brasileira, v. 2, p. 21. 
Modernismo, considerando a retomada da questão do nacional, Oswald de Andrade, com o movimento antropofágico e Mário de Andrade, com a publicação de Macunaima (1928), ilustram as tendências predominantes.

Nas páginas finais do estudo, a autora de As formas do falso observa como o enfoque sobre o índio retorna na segunda metade do século XX, com a discussão do Imperialismo. Essas considerações contextualizam a menção ao conto Meu tio, o iauaretê, de Guimarães Rosa e, ainda, ao romance Maíra. O panorama, realizado por Walnice Nogueira Galvão sobre a presença do índio na literatura brasileira, lança as bases para estudos comparatistas como entre Maíra e textos da literatura brasileira ${ }^{4}$ e Maíra e obras de outras literaturas.

No Brasil, nos anos 80, no âmbito de temas afins com a questão do índio na literatura, ressalto a crítica de Lígia Chiappini Moraes Leite, ${ }^{6}$ inserida no livro O nacional e o popular na cultura brasileira. Sua abordagem incide sobre a obra de Antonio Callado.

$\mathrm{Na}$ seção "Indianismo repensado", pertencente ao capítulo "A Expedição Montaigne outras", referindo-se ao estudo de Walnice Nogueira Galvão, salienta que a autora de Mitológica rosiana "deixa de mencionar Quarup, que também trata do índio". ${ }^{7}$ A autora do capítulo, embora não tenha a intenção de aprofundar a comparação entre Quarupe Maíra, aponta aproximações e diferenças entre os dois romances. Em relação às semelhanças, destaco: "espécie de elogio implícito, nos dois livros, da forma de vida indígena capaz de fornecer lições básicas à civilização branca e cristã"; a aproximação entre Alma e Sônia; a relação de Isaías "ora

4. Cito como exemplos: SÁ. A literatura entre o mito e a história, p. 303; COELHO. A retórica da morte e sua contrapartida em Maíra de Darcy Ribeiro e Concerto carioca, p. 89-96; CALDEIRA. Revisitando o ethos indígena e a Nação no caminho da construção das identidades, 163 p.; OLIVIA DOS SANTOS. O percurso da identidade na literatura brasileira: matrizes da figuração, 360 p.

5. Veja-se o texto MARQUES. Visões da morte no indigenismo de Darcy Ribeiro e Jorge Icaza, p. 145-161.

6. LEITE. Quando a pátria viaja: uma leitura dos romances de Antonio Callado.

7. LEITE. Quando a pátria viaja: uma leitura dos romances de Antonio Callado, p. 231.

8. LEITE. Quando a pátria viaja: uma leitura dos romances de Antonio Callado, p. 231. 
com Nando, ora Fontoura"; o modo como "se celebra a alegria de viver de um povo mesmo moribundo" e a denúncia da "pulsão destrutiva da civilização ocidental".

Lígia Chiappini evidencia também que há diferenças profundas entre os dois romances. Quarup encontra-se mais próximo do "realismo lukacsiano". Em Maíra, ocorre o "estilhaçamento do ponto de vista". ${ }^{12}$ O romance Expedição Montaigne (1982) também possibilita confrontos com o romance de Darcy Ribeiro. No livro de Antonio Callado, "a religião está desacreditada, os mitos indígenas aparecem como mentira e o amor não tem nenhuma oportunidade". ${ }^{13}$ A "agonia da cultura indígena" aparece nas duas últimas obras comentadas. Segundo Lygia, “(...) Callado aprofunda também a crítica ao idealismo desse intelectual salvador, abrindo uma dimensão quase ausente em Maíra".

Estudando o exílio de Darcy Ribeiro no Uruguai, mostrei que a discussão do papel do intelectual estava presente em textos teóricos, decorrentes de seminários dos quais o escritor brasileiro participou e que dirigiu na Universidad de La República. E, se naquele momento, anos 60 e 70, o escritor acreditava no papel do intelectual que poderia intervir nas mudanças sociopolíticas, este pensamento permaneceu até o último momento de sua vida conjugada com a prática política. Quando faleceu em 1997, exercia o cargo de senador da República. Em 1996, publica Diários índios, texto de que trataremos mais adiante. Nesse livro, a propósito do intelectual, observa:

Intelectual, para mim, é pois, aquele que melhor domina e expressa o saber de seu grupo. Saberes copiosíssimos, como o dos índios sobre a natureza e o humano, ativados por uma curiosidade acesa de gente que se acha capaz de compreender e explicar tudo. São saberes mais

9. LEITE. Quando a pátria viaja: uma leitura dos romances de Antonio Callado, p. 231.

10. LEITE. Quando a pátria viaja: uma leitura dos romances de Antonio Callado, p. 231.

11. LEITE apud GALVÃO. Indianismo revisitado, p. 231.

12. LEITE. Quando a pátria viaja: uma leitura dos romances de Antonio Callado, p. 232.

13. LEITE. Quando a pátria viaja: uma leitura dos romances de Antonio Callado, p. 233.

14. LEITE. O nacional e o popular na cultura brasileira, p. 233. 
modestos, frutos de uma lusitana tradição oral, vetusta, ou de heranças culturais de outras matrizes, como a de nossos sertanejos. ${ }^{15}$

Embora a ironia seja um aspecto mostrado em Expedição Montaigne por Lígia Chiappini, no âmbito do confronto, não se estende ao romance Maíra. Em 1995, ao publicar o artigo intitulado "A retórica da morte e sua contrapartida em Maíra de Darcy Ribeiro e Concerto carioca de Antonio Callado", ${ }^{16}$ evidenciei a presença da ironia e do humor com base nas metáforas espaciais: a travessia em Maíra (1976) e o labirinto em Concerto carioca (1985). A referência a este último romance, de Antonio Callado, tem como objetivo mostrar que o índio continuou na literatura do autor, depois de Expedição Montaigne. Em Concerto carioca, o índio aparece deslocado na cidade, especialmente no Jardim Botânico, no Rio de Janeiro.

$\mathrm{Na}$ relação entre a representação indígena e o discurso da nação, que aparece desde o Romantismo, atento para a dissertação de Claudia Passos Caldeira, ${ }^{17}$ que enfocou esse aspecto, tendo em vista três momentos: no século XIX ("modelos distintivos de representação, atinente ao Romantismo e o presente nos textos de viajantes, naturalistas e cientistas"); nos anos 20 e 30 do século XX (Macunaima e Casa-Grande \& Senzala); entre 1960 e 1970 (com destaque para o romance Maíra) e os anos 90 ("reafirmação das identidades étnicas" com base em "Ore awé roiru a'ma”, de Kaká Werá Jecupé).

Antes de escrever seus textos literários, Darcy Ribeiro produziu uma extensa e complexa obra antropológica. Tendo gestado parte dessa obra no exílio uruguaio, em carta enviada ao Dr. Arturo Ardao, Diretor da Facultad de Humanidades, faz um resumo de várias de suas atividades. Dentre elas, destaca a elaboração de seus livros, que são por ele resumidos. O recuo no tempo, por meio dessa correspondência, é importante. De acordo com o tema deste ensaio, atenho-me ao comentário feito por ele em relação ao livro Os índios e a civilização. Darcy Ribeiro resume seu livro da seguinte maneira:

Este é um estudo do processo de integração das populações indígenas no Brasil moderno. A respectiva investigação de campo foi realizada

15. RIBEIRO. Diários índios, p. 545.

16. Coelho. A retórica da morte e sua contrapartida em Maíra de Darcy Ribeiro e Concerto carioca de Antonio Callado, p. 89-95.

17. CALDEIRA. Revisitando o ethos indígena e a Nação no caminho da construção das identidades, p. 7. Esta dissertação foi orientada por mim. 
entre 1950 e 1955, como parte de um programa de estudos do Departamento de Ciências Sociais da UNESCO sobre relações de raça no Brasil. Seus resultados foram parcialmente divulgados em forma de artigos em diversas revistas especializadas. Compendiado, agora, como livro, será publicado, em 1959, pela editora Civilização Brasileira, em português. A tradução inglesa está sendo preparada para sua publicação pela Columbia University Press e a edição espanhola será contratada, provavelmente, pela Editora da Universidade Central da Venezuela. ${ }^{18}$

Em 2001, João Pacheco de Oliveira escreveu um capítulo dedicado à obra Os índios e a civilização, mostrando que esse livro "deveria ser colocado dentro de um conjunto seleto de obras que constituem uma referência básica para o pensamento social brasileiro, ao lado dos clássicos como Casa-Grande Esenzala ou Raízes do Brasil". ${ }^{19}$ Em relação ao mesmo estudo de Darcy Ribeiro, o antropólogo afirma:

Em termos de informação e sistematização de dados, esse livro continua a ser uma peça insubstituível, referência obrigatória para qualquer apreciação global da população indígena brasileira. A compreensão do processo de transfiguração étnica, dos mecanismos de exclusão atuantes na sociedade brasileira, dos fatores extralocais, nacionais e internacionais, que interferem e definem os limites da interação entre índios e brancos no Brasil, continuam a ser diretivas importantes e atuais para a investigação antropológica. $^{20}$

No âmbito da produção literária de Darcy Ribeiro, além de Maíra, a questão indígena retorna no livro Utopia selvagem: saudades da inocência perdida: uma fábula (1982). Como já mostrei em trabalho anterior, ${ }^{21}$ Darcy Ribeiro vale-se de várias linguagens e de diferentes textos. O caráter antropofágico do livro comunica-se com a tradição modernista. A figura de Calibã na fábula, se por um lado, remete à peça $A$ tempestade, de Shakespeare, por outro, se relaciona com

18. RIBEIRO. Carta enviada ao Professor Arturo Ardao, 10 jun. 1968, p. 4 (Tradução minha).

19. Oliveira. Os índios e a civilização, p. 406.

20. OLIVEIRA. Os índios e a civilização, p. 421.

21. Cf. COelho. (Org.). Darcy Ribeiro, p. 25-26. 
Calibán y otros ensayos, de Roberto Fernández Retamar, poeta e crítico cubano com o qual Darcy Ribeiro manteve uma importante interlocução no período de seu exílio e pós-exílio. A inserção da fábula, no debate político e latino-americano, se torna de fundamental importância, pois Darcy Ribeiro situa a questão indígena no âmbito do Brasil e da América Latina, em relação às várias fontes europeias.

Maíra, ao apresentar visões diferenciadas sobre os índios a partir de si mesmos e dos brancos, ${ }^{22}$ civilizados, traz potencialmente o diálogo com uma gama variada de textos: com aqueles da literatura brasileira a que já nos referimos a partir dos estudos de Walnice Nogueira Galvão e Lígia Chiappini M. Leite; com textos de outras literaturas em que a questão indígena está presente e, ainda, com textos antropológicos do escritor, que refletiu sobre o Brasil e a América Latina.

O romance Maíra, ao encenar a passagem do mito ao romance, ${ }^{23}$ possibilita focalizar o encontro entre índios e neocolonizadores, no âmbito do capitalismo, nos meados dos anos 70, mas também os discursos daqueles que construíram ideias sobre nós. Para isso, valho-me de alguns textos e referências que aparecem em A fundação do Brasil, organizado por Darcy Ribeiro e Carlos de Araújo Moreira Neto, a pedido da Coleção "Biblioteca Ayacucho", da Venezuela, por ocasião dos "500 anos da chegada dos europeus às Américas". 24

\section{A fundação do Brasil: olhares e idéias sobre o Brasil e os índios}

O livro A fundação do Brasil traz uma introdução intitulada "A invenção do Brasil", escrita por Darcy Ribeiro, que comenta muitos aspectos que vão ser lidos nos documentos. O texto da "invenção" abriga os seguintes subitens: "Bulas e burlas", "Paraíso e utopias", "O Brasil e os brasis", "A indianidade", "As anti-utopias", "As pestes da civilização", "Os brasileiros", "Matrizes étnicas", "A empresa Brasil", "A possessão" e "Epílogo".

Conforme se mostra pelos subtítulos apresentados, a introdução inclui documentos oficiais sobre a descoberta do Brasil e da América. A construção de

22. Cf. Coelho. Exumação da memória.

23. Cf. Coelho. Exumação da memória, p. 1

24. RIBEIRO; MOREIRA NETO (Org.). A fundação do Brasil, p. 8. 
utopias, geradas pelas imagens do paraíso terreal, encontra sua contrapartida nas anti-utopias que são: "a anti-utopia teológica e a mercantil".

Antes de nossa existência, fomos traçados por "Bulas" que se transformaram em "burlas". São elas: a "Bula Romanus Pontifex, de 1454, em que o Papa Nicolau V legaliza e sacramenta a expansão europeia" e a "Bula Intercetera, de 1493, em que um Papa Borgia, Alexandre VI, apenas um ano depois da expedição de Colombo, estende aos Reis da Espanha o que seu antecessor dera ao príncipe D. Henrique: o direito de apropriar-se do Novo Mundo e de escravizar os povos nativos que encontrasse aqui, chamados índios, porque se supunha que fossem orientais". 27 O outro documento ressaltado é o Tratado de Tordesilhas (1494), em que os "Reis de Portugal e da Espanha, com aprovação do Santo Padre, acordam em dividir entre eles dois o mundo extra-europeu". ${ }^{28}$

"A invenção do Brasil", de Darcy Ribeiro, ao focalizar "Os brasileiros", dialoga de perto com Opovo brasileiro: a formação e o sentido do Brasil, publicado em 1995. No decorrer da apresentação do livro, organizado por Darcy Ribeiro e Carlos de Araújo Moreira Neto, há uma postura crítica em relação às fontes que nos idealizaram e, ainda, de denúncia, no que se refere ao projeto civilizatório com base em uma anti-utopia, assentada no genocídio étnico.Veja-se o trecho marcado pela ironia:

O maior susto que tiveram os portugueses, no passado, foi ver a força de trabalho, reunida no Brasil com propósitos imediatamente mercantis, para ser aqui queimada na produção, se insurgir, pretendendo ser tida como gente com veleidades de autonomia e de autogoverno. Do mesmo modo, a grande perplexidade das classes dominantes atuais do Brasil é que os descendentes daqueles negros, índios e mestiços ousem pensar que este país é uma república que deve ser dirigida pela vontade do povo em busca de sua própria felicidade. ${ }^{29}$

25. RIBEIRO. In: RIBEIRO; MOREIRA NETO (Org.). A fundação do Brasil, p. 25 .

26. RIBEIRO; MOREIRA NETO (Org.). A fundação do Brasil, p.16.

27. RIBEIRO; MOREIRA NETO (Org.). A fundação do Brasil, p. 17.

28. RIBEIRO; MOREIRA NETO (Org.). A fundação do Brasil, p. 17.

29. RIBEIRO. In: RIBEIRO; MOREIRA NETO (Org.). A fundação do Brasil, p. 61. 
Considerando os inúmeros aspectos do livro A fundação do Brasil, atenho-me à terceira parte intitulada "O mundo índio". Nela algumas imagens do bom selvagem são mostradas, com base nos escritos de Jean de Léry, Claude D’Abbeville e Michel de Montaigne.

Jean de Léry, por exemplo, mostrava como os tupinambá recebiam "com muita cordialidade os estrangeiros que os vão visitar.". A "caridade natural" também é evidenciada por Léry, que registra como, depois de ter passado por um grande perigo, os franceses voltaram à aldeia que os acolheu, sendo muito bem recebidos. Em relação aos comentários de Claude d'Abbeville e Yves d'Evreux sobre os índios, afirmam os organizadores do livro sobre a fundação do Brasil:

O que há de distintivo nas obras de Abbeville e Evreux é o fato de que são, provavelmente, os últimos registros do período colonial em que os índios, suas instituições, costumes e sua visão de mundo são matéria capaz de despertar o interesse intelectual e a simpatia dos observadores. ${ }^{31}$

Ao referirem-se à visão de Michel de Montaigne, Darcy Ribeiro e Carlos Moreira Leite ressaltam que o filósofo francês, além de ter tido "acesso a obras fundamentais sobre a América", 32 entrou em contato com "truchements ou intérpretes, que acompanharam as várias expedições francesas ao novo mundo, particularmente ao Brasil". ${ }^{33}$ Além disso, Montaigne "teve um longo contato pessoal com um grupo de nativos levados ao Ruão para uma demonstração em honra do rei Carlos IX".

A crueldade sobre os índios e o desrespeito pelos seus ritos podem ser constatados pela transcrição de uma carta do Padre Manuel da Nóbrega, datada da Bahia em 5 de julho de 1559. Destinada aos "Padres e irmãos de Portugal", revela como um "feiticeiro" indígena teve seu saber desqualificado e foi levado a um terreiro, para que fosse queimado por todos aqueles que se encontravam na aldeia. Nesse ato exemplar, cada um levou "seu tição do lume e a lenha que

30. RiBEIRO; MOREIRA NETO (Org.). A fundação do Brasil, p. 159.

31. RIBEIRO; MOREIRA NETO (Org.). A fundação do Brasil, p. 61.

32. Ribeiro; MOREIRA NeTO (Org.). a fundação do Brasil, p. 163.

33. Ribeiro; MOREIRA NETO (Org.). a fundação do Brasil, p. 163.

34. RIBEIRO; MOREIRA NETO (Org.). A fundação do Brasil, p. 163. 
pudessem". Tudo indica que o padre Manuel da Nóbrega acabou por conduzir o índio "para se doutrinar".

O término do documento, lido sob uma perspectiva crítica, mostra como o medo e a violência sobre os corpos constituíram modos utilizados para que os índios fossem submetidos igualmente pela religião e pelo processo colonizador. O caráter conclusivo da Carta reitera a noção de exemplaridade: "Desta maneira está a terra agora e esta é a condição do Gentio e todavia o pai e a mãe do menino consentiram depois que lhes batizassem o filho." ${ }^{36}$

"O mundo índio" traz ainda "Retratos do civilizador". Estes são mostrados com base em transcrições do livro de Claude D'Abbeville, referentes "às palavras de um velho cacique indígena Tupinambá”; parte do discurso de Jupiaçu, "grande morubixaba da Ilha do Maranhão" e, ainda, "Cartas de Pedro Poti e Antonio Paraupaba" (1645-1656).

O primeiro texto mostra como Momboré-açu, chefe indígena Tupinambá, revela semelhanças entre as ações dos colonizadores portugueses e franceses: a obrigatoriedade do batismo; a escravização dos índios; a recusa do casamento com as mulheres indígenas engravidadas tanto por portugueses quanto por franceses.

O discurso de Japi-açu é marcado pela recusa dos portugueses e a aceitação dos franceses, vistos como "nossos bons amigos". Essa atitude receptiva estende-se à abertura para a religião dos franceses, responsáveis por dar a conhecer o Deus dos brancos. Veja-se o trecho:

Aliás estou grandemente satisfeito com o fato de nos teres trazido Paí e profetas, pois os malditos peró que tanto mal nos fizeram não faziam outra coisa senão censurar-nos não adorarmos a Deus. Miseráveis! Como poderíamos adorá-lo, se não nos ensinavam antes a conhecê-lo e adorá-lo?

35. Ribeiro; MOREIRA NETO (Org.). A fundação do Brasil, p. 215.

36. RIBEIRO; MOREIRA NETO (Org.). A fundação do Brasil, p. 215. Na Carta, o padre Manuel da Nóbrega mostra como um menino não ia ser batizado pelos pais indígenas, porque o "feiticeiro" os tinha convencido de não fazê-lo. No entanto, o padre obriga os pais a batizar o filho, buscando também doutrinar o "feiticeiro".

37. RIBEIRO; MOREIRA NETO (Org.). A fundação do Brasil, p. 227. 


\section{"O enfrentamento dos mundos" em Opovo brasileiro: $a$ formação e o sentido do Brasil}

O encontro entre índios e brancos, no período da conquista e consequente colonização, é mostrado em outro livro do antropólogo. Trata-se de O povo brasileiro: a formação e o sentido do Brasil, publicado em 1995. Especificamente no capítulo "Enfrentamento dos mundos", de maneira inventiva, Darcy Ribeiro traduz este encontro. Introduz dúvida na perspectiva indígena, representada pelo olhar de Maíra para quem os recém-chegados colonizadores poderiam ser "ferozes como pacíficos, espoliadores ou dadores".

Considerando os adjetivos em oposição, verifica-se que há uma síntese de imagens, decorrentes de textos de viajantes e de colonizadores. O "enfrentamento", sob o olhar indígena, mediado pela palavra do autor, é mostrado de forma crítica. No mesmo capítulo de Opovo brasileiro: a formação e o sentido do Brasil, a morte do deus Maíra, anunciada em "Mairañee" (no romance Maíra), reaparece de forma interrogativa:

Pouco mais tarde essa visão idílica se dissipa. Nos anos seguintes, se anula e reverte-se no seu contrário: os índios começam a ver a hecatombe que caíra sobre eles. Maíra, seu deus, estaria morto? Como explicar que seu povo predileto sofresse tamanhas provações? Tão espantosas e terríveis eram elas, que para muitos índios melhor fora morrer do que viver. ${ }^{39}$

Ainda, no capítulo mencionado, há o confronto entre a visão de mundo dos índios e a dos brancos. O uso do pretérito imperfeito traz o passado para o presente:

Para os índios, a vida era uma tranquila fruição da existência, num mundo dadivoso e numa sociedade solidária. [...] Para os recém chegados, muito ao contrário, a vida era uma tarefa, uma sofrida obrigação, que a todos condenava ao trabalho e tudo subordinava ao lucro. ${ }^{40}$

38. RIBEIRO. O povo brasileiro: a formação e o sentido do Brasil, p. 42.

39. RIBEIRO. O povo brasileiro: a formação e o sentido do Brasil, p. 43.

40. RiBEIRO. O povo brasileiro: a formação e o sentido do Brasil, p. 47. 
Considerando que Darcy Ribeiro institui um diálogo com as fontes recolhidas dos textos da "fundação", destaco, ainda, em O povo brasileiro, um trecho extraído da obra de Jean de Léry (que é uma conversa entre o viajante francês e um velho tupinambá) e a referência a " 2 mil versos de louvação escritos em latim por José de Anchieta (1958: 129) no poema 'De Gestis Mendi de Saa' (circa 1560)". "A1 A menção a este último texto se justifica pelo fato de Mém de Sá ter executado "rigorosamente o plano de colonização proposto pelo padre Nóbrega em 1558". 42

Em "O enfrentamento dos mundos", as contradições do projeto civilizador, empreendido pelos jesuítas, também são reveladas:

A atuação mais negativa dos jesuítas, porém, se funda na própria ambigüidade de sua lealdade frente aos índios e à Coroa, mais predispostos, porém a servir a esta Coroa contra índios aguerridos que a defendê-los eficazmente dela. Isso sobretudo no primeiro século, quando sua função principal foi minar as lealdades étnicas dos índios, apelando fortemente para o seu espírito religioso, a fim de fazer com que se desgarrassem das tribos e se atrelassem às missões. A eficácia que alcançam nesse papel alienador é tão extraordinária quanto grande a sua responsabilidade na dizimação que dela resultou. ${ }^{43}$

Se, em O povo brasileiro: a formação e o sentido do Brasil, no capítulo "Enfrentamento dos mundos", Darcy Ribeiro combina fontes históricas, antropológicas e ficcionais, dando destaque ao olhar dos índios sobre os colonizadores; em Diários índios, o leitor pode acompanhar o registro da viagem do antropólogo às aldeias dos Urubus-Kaapor entre 1949 e 1951.

\section{De "Egosum" a Diários indios}

Quando lê Maíra, o leitor se depara com o capítulo "Egosum", bem diferente daqueles que vão sendo narrados no romance. A novidade reside no caráter autobiográfico do texto que reúne, de forma fragmentária, imagens, fagulhas

41. RIBEIRO. O povo brasileiro: a formação e o sentido do Brasil, p. 50.

42. RIBEIRO. O povo brasileiro: a formação e o sentido do Brasil, p. 50.

43. RIBEIRO. O povo brasileiro: a formação e o sentido do Brasil, p. 56. 
da memória do escritor, cujas ressonâncias vão compondo um painel complexo formado de elementos diversos da biografia de Darcy Ribeiro. Admitir o caráter autobiográfico, presente em "Egosum", no entanto, não significa ver Maíra como reflexo da experiência do antropólogo. Isso seria uma visão redutora do romance. Em "Egosum", há o registro da memória de uma forma múltipla, relativa a diferentes experiências. Entre estas estão momentos vividos pelo narrador/escritor entre os índios, o que possibilita aproximar "Egosum" dos registros de Diários índios, obra publicada vinte anos depois de Maíra (1996).

Em "Egosum", o autor mistura fontes. Dentre estas assinalo, por exemplo, a experiência de Uirá, que é narrada em Uirá sai à procura de Deus: ensaios de etnologia e indigenismo. Se, no relato antropológico, Darcy Ribeiro mostra que conheceu a história de Uirá como fato, "na vila de São Pedro, no Maranhão, onde ele se matou", ${ }^{44}$ em Maíra, o narrador descreve o mesmo acontecimento como se ele tivesse visto o homem que "se declarou inharon".

Quando Darcy Ribeiro publica Diários índios (1996) estava com câncer e sabia que tinha pouco tempo de vida. O texto é escrito sob a forma de carta, de carta de amor a Berta, sua primeira esposa. No registro da viagem de campo, há várias menções às missivas endereçadas à antropóloga. Tomando o livro como grande carta, esta engloba as demais.

A primeira expedição começa em Vizeu, em 20 de novembro de 1949 e o retorno ocorre em 11 de abril de 1950. A primeira viagem do antropólogo foi realizada com Max Boudin, linguista, e Heinz Foerthmann, cinegrafista. O objetivo era estudar "os descendentes dos velhos Tupinambá", 45 cujo registro fora realizado por Alfred Métraux e Florestan Fernandes.

Em seus diários, o autor registra os homens, suas festas, seus costumes e a presença de estrangeiros nos diversos lugares onde passa como, por exemplo, sírios em Vizeu ${ }^{46}$ e David Blake ("ex-ministro protestante que veio fundar uma missão no alto Gurupi”). ${ }^{47}$ Ao longo do relato da viagem até à tribo dos índios "Urubus- Kaapor", anota "os cantos do falso pajé"; ${ }^{48}$ a "Pajelança de Maria

44. RIBEIRO. Uirá sai à procura de Deus: ensaios de etnologia e indigenismo, p. 17.

45. RIBEIRO. Diários índios, p. 17.

46. RIBEIRO. Diários índios, p. 17.

47. Cf. RIBEIRO. Diários índios, p. 43.

48. Cf. RIBEIRO. Diários indios, p. 56. 
Rodrigues"; "a forma local das Festas de Coroação do Imperador ou da Imperatriz" "50 e o cantador que "tira a toada (estribilho) e vai pondo versos" ${ }^{51}$ na festa do " Bumba-meu-Boi".

Em seus escritos, o antropólogo demonstra as várias dificuldades enfrentadas por ele, incluindo aquela de encontrar o melhor intérprete. Testemunha, ainda, a morte de muitos índios e o desaparecimento de aldeias decorrentes de doenças transmitidas pelos brancos, sobretudo o sarampo.

Para dar uma ideia a Berta dos índios com os quais está convivendo, vai fazer retratos como aqueles que se encontram descritos em suas anotações de 12 de janeiro de 1950. Darcy Ribeiro destaca em Ianawakú, chefe de uma das aldeias visitadas, várias qualidades como a de "artífice exímio em trabalhos de penas" ${ }^{, 53}$ e de respeitado chefe que "não se impõe à força" ${ }^{54}$

Entre os índios, Darcy Ribeiro observa o olhar deles para sua escrita como em "olham apalermados para minha pena correndo no papel". No entanto, não se limitam ao gesto visual e, ao desejarem "experimentar a caneta" (... $)^{56}$ "sugeriram que [ele] desenhasse uma moça"(...). O gesto é seguido pelos índios que também registram o desenho na caderneta do antropólogo.

Em 2 de agosto de 1951, quando o autor de Maíra começa a anotar a segunda expedição às aldeias kaapor, "partindo da margem do rio Pindaré, no centro do Maranhão" perdido neste nosso século e também orgulho-me de não estar procurando nessas viagens os mesmos objetivos que eles - a preia e o saqueio".

49. Cf. Ribeiro. Diários índios, p. 57-58.

50. RIBEIRO. Diários índios, p. 59-60.

51. RIBEIRO. Diários índios, p. 61.

52. RIBEIRO. Diários índios, p. 61-63.

53. RIBEIRO. Diários índios, p. 151.

54. RIBEIRO. Diários índios, p. 151.

55. RIBEIRO. Diários índios, p. 125.

56. RIBEIRO. Diários índios, p. 131.

57. RIBEIRO. Diários índios, p. 299.

58. RIBEIRO. Diários índios, p. 299.

59. RIBEIRO. Diários índios, p. 299. 
O registro da viagem do antropólogo tem um caráter político. Denuncia as más condições dos postos indígenas, as situações de pobreza e miséria vividas pelos índios e pelas populações de lugarejos e vilas igualmente marginalizados. No decorrer do diário, o antropólogo mostra como atua também na realidade que observa. Nesse caso, não vê de forma passiva o sofrimento e a morte dos índios:

Todos os dias de manhã, temos nossa sessão de tratamento.Vêm todos os que têm doença pedir puhang. O caso mais grave é o do filho do capitão que tem uma ferida no pé que já lhe deu uma enorme íngua supurada na virilha, chagas feias que tenho esprimido e tratado sem grande resultado. Por isso the apliquei hoje uma penicilina, vamos ver o resultado.

O livro dos diários compõe-se de vários textos como histórias, versões de mitos, cartas administrativas, fotos, desenhos feitos pelo antropólogo e pelos índios, mapas, cantos, enfim uma variedade que reitera sua importância, além da informação antropológica. Ao ultrapassar fronteiras disciplinares, estabelece uma conexão com os mais diferentes saberes e textos de Darcy Ribeiro. O autor evidentemente tinha consciência disso e nos propiciou mais este legado antes de falecer em 17 de fevereiro de 1997.

De forma panorâmica, mostrei como Darcy Ribeiro enfocou a questão indígena em alguns de seus vários textos (literários, antropológicos e autobiográficos, no caso Diários índios) e no livro organizado por ele e Carlos de Araújo Moreira Neto. Para essa tarefa, foi necessário fazer recortes e revisitar caminhos críticos. A obra de Darcy Ribeiro é bastante extensa e a bibliografia sobre ele tem aumentado significativamente. Além do que se observou, é importante ressaltar que o escritor, ao projetar a memória de si e dos seus textos, associou sua vida e memória à existência dos índios brasileiros.

O "Memorial Darcy Ribeiro", inaugurado em 6 de dezembro de 2010, em Brasília, sob a forma de oca, não foi construído ${ }^{61}$ dessa forma por acaso. Sob a perspectiva deste texto e de outros trabalhos escritos por mim a respeito da memória na obra de Darcy Ribeiro, o "Memorial" constitui a memória edificada de

60. RIBEIRO. Diários índios, p. 133.

61. O projeto do "Memorial Darcy Ribeiro" foi realizado pelo arquiteto João Filgueiras Lima. 
Darcy Ribeiro e da aldeia cuja imagem ele guardou como um mapa, tal como fez Isaías, personagem do romance Maíra. Isaías trazia dentro de si o espaço vivido e Darcy Ribeiro conservou este mapa que se projeta para o futuro, aliando tempos do presente e do passado. O testemunho do vivido pode ser lido e visto de inúmeras maneiras no espaço da Universidade de Brasília que ele idealizou. Hoje, a literatura feita por índios mostra que o monumento não apaga a memória e nem nele ela se cristaliza. A reflexão sobre os índios, a partir de uma perspectiva do presente, do passado e do futuro, pertence a Darcy e Berta Ribeiro cuja lembrança foi evocada a partir de Diários índios. Berta abriu outros caminhos para a reflexão sobre a literatura escrita pelos índios. No entanto, este é um outro aspecto da representação literária e suas múltiplas interfaces.

Darcy Ribeiro: the question of the Brazilian natives, literary representation and its multiple interwoven aspects

Abstract: So that I can discuss questions of the natives, literary representation and its various connections, based on some texts written by Darcy Ribeiro, I start with the theme of Indianism in literature, which Walnice Nogueira Galvão revisited in an essay after the publication of Maíra in 1976. Then I go on to other studies and highlight the fact that, before publishing his first novel, Darcy Ribeiro came up with an important, extensive and complex body of anthropological work, among which features Natives and civilization (Os índios e a civilização). By presenting different looks upon the natives from their own point of view and from that of the civilized white men, Maira brings the possibility of a dialogue with a great variety of historical and anthropological texts like A fundação do Brasil (The creation of Brazil), a collection organized by Darcy Ribeiro and Carlos de Araújo Moreira Neto, and $\mathrm{O}$ povo brasileiro: a formação e o sentido do Brasil (The Brazilian people: the formation and meaning of Brazil), especially the chapter "Enfrentamento dos mundos" ("Facing worlds"). In Diários índios (The Indian diaries), Darcy Ribeiro narrates chronologically his trip to the north of the country in order "to study the descendants of the old Tupinamba people", something that brought the opportunity to focus the contact between the anthropologist and the natives as well as their look into the writings of the white man about them. The width of Diários indios helped to highlight the general aspects of the book.

Keywords: Questions of the natives, Literary representation, Darcy Ribeiro. 


$$
\text { Referências }
$$

CALDEIRA. Revisitando o ethos indígena e a nação no caminho da construção das identidades. 2006. 163p. Dissertação (Mestrado) - Faculdade de Letras, Universidade Federal de Minas Gerais, Belo Horizonte, 2006.

CANDIDO. Formação da literatura brasileira: momentos decisivos. 3. ed. São Paulo: Martins, 1969. v. 2.

COElHO, Ribeiro Haydée (Org.). Darcy Ribeiro. Belo Horizonte: Centro de Estudos Literários da UFMG, Curso de Pós-Graduação em Letras - Estudos literários, 1997.

COElHO. A retórica da morte e sua contrapartida em Maíra de Darcy Ribeiro e Concerto Carioca. Boletim do Centro de Estudos Portugueses. Belo Horizonte, Faculdade de Letras, Universidade Federal de Minas Gerais, v.15, n.19, p. 89-96, jan/dez. 1995.

COElHO. Exumação da memória. 1989. 212 f. Tese (Doutorado) - Universidade de São Paulo, São Paulo, 1989.

GALVÃO, Walnice Nogueira. Indianismo revisitado. In: Gatos de outro saco: ensaios críticos. São Paulo: Brasiliense, 1981.

LEITE, Lígia Chiappini Moraes Leite. Quando a pátria viaja: uma leitura dos romances de Antonio Callado. In: ZILIO, Carlos et al. (Org.). O nacional e o popular na cultura brasileira. São Paulo: Brasiliense, 1982.

MARQUES, Paulo Sérgio. Visões da morte no indigenismo de Darcy Ribeiro e Jorge Icaza. Gragoatá. Revista do Programa de Pós-Graduação em Letras. Relações latinoamericanas, Niterói, Universidade Federal Fluminense, n.22, p.145-161, 2007.

OLIVEIRA, João Pacheco de. Os índios e a civilização. In: MOTA, Lourenço Dantas. Introdução ao Brasil: um banquete no trópico. São Paulo: SENAC, 2001.

OLIVIA DOS SANTOS, Luzia de Maria. Opercurso da identidade na literatura brasileira: matrizes da figuração. 2008. 360p. Tese (Doutorado) - Universidade Estadual Paulista Julio de Mesquita Filho, São José do Rio Preto, 2008.

RIBEIRO, Darcy; MOREIRA NETO, Carlos de Araújo (Org.). A fundação do Brasil: testemunhos 1500-1700. 2. ed. Petrópolis: Vozes, 1993.

RIBEIRO, Darcy. Maíra. 5. ed. Rio de Janeiro: Civilização Brasileira, 1981.

RIBEIRO, Darcy. O povo brasileiro: a formação e o sentido do Brasil. São Paulo: Companhia das Letras, 1995.

RIBEIRO, Darcy. Uirá sai à procura de Deus: ensaios de etnologia e indigenismo. 2. ed. Paz e Terra: Rio de Janeiro, 1976.

RIBEIRO, Darcy. Carta enviada ao Professor Arturo Ardao, 10 jun, 1968.

RIBEIRO, Darcy. Diários índios: Os Urubus-Kaappor. São Paulo: Companhia das Letras, 1996.

SÁ, Lúcia Regina. A literatura entre o mito e a bistória: uma leitura de Maíra e Quarup. 1990. 303p. Dissertação (Mestrado) - Universidade de São Paulo, São Paulo, 1990. 